\title{
SCIENCE
}

\begin{abstract}
Friday, February 11, 1916
CONTENTS

The American Association for the Advancement of Science:-

The Dependence of Progress in Science on the Development of Instruments: PROFESSOR

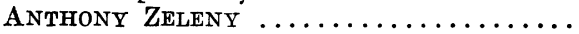

Psychological and Historical Interpretations for Culture: DR. CharK WISsLer ........ 193

Charles René Zeiller: E. W. B. ........... 201

Recommendations of the Pan-American Scientifi: Congress ....................

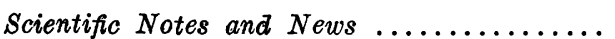

University and Educational News

Discussion and Correspondence:-

Parasites of the Muskrat: DR. FRANKLIN D. BARKER. The Use of the Injection Process in Class Work in Zoology: RAPHAEL IsAACS. The Poisonous Character of Rose Chafers: J. M. Bates ................... 208

Scientific Books:-

The British Antarctic Expedition: DR. WM.

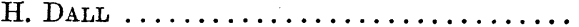

The Proceedings of the National Academy of Sciences: EdwIN BIDWELL WILson .......

Notes on Meteorology and Climatology: Charles F. Brooks ..................

Special Articles:-

The Development of the Phylloxera vasatrix Leaf Gall: HARRY R. RoseN ............

The Quarter-centennial Anniversary of the Ohio Academy of Sciences: Professor Ed-

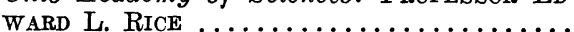

The Tennessee Academy of Science: Roscot

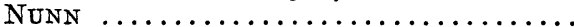

Societies and Academies:-

The Botanical Society of Washington: PERLEY SPAulding. The Anthropological Society of Washington: DANIEL FOLKMAR ... 219

MSS. intended for publication and books, etc., intended for review should be sertt to Professor J. McKeen Cattell, Garrisonon-Iudson. N. Y.

\section{THE DEPENDENCE OF PROGRESS IN SCIENCE ON THE DEVELOPMENT OF INSTRUMENTS 1}

OUR civilization is requiring for its physical welfare a more and more intimate knowledge of nature's forces. It is demanding this knowledge faster than it is being produced as a by-product in our educational institutions. Scientific investigation is becoming a large business. Governments have established research laboratories; private individuals have endowed others; universities are making more strenuous efforts than ever to encourage research and to make it a real part of their function; and commercial enterprises are finding it profitable to establish research laboratories on a large scale, not being able to wait for the random discoveries from other sources. These facts, alone, show that science is rendering an indispensable service.

The factors which are involved in the solution of scientific problems are in part mental and in part physical. Long experience has taught that however much we may owe to the great minds that evolve basic generalizations and hypotheses, real progress in science ultimately rests on the establishment of facts. Our reasoning faculties, by themselves, are unable to cope with the complexity of the physical world, and are sure to stray from reality unless they are continually guided by observation and experiment. Galileo with his experimental methods contributed more to sci-

1 Address of the vice-president and chairman of Section B-Physics, American Association for the Advancement of Science, Columbus, December, 1915. 


\section{Science}

\section{3 (1102)}

Science 43 (1102), 185-220.

ARTICLE TOOLS

PERMISSIONS http://science.sciencemag.org/content/43/1102.citation

http://www.sciencemag.org/help/reprints-and-permissions 